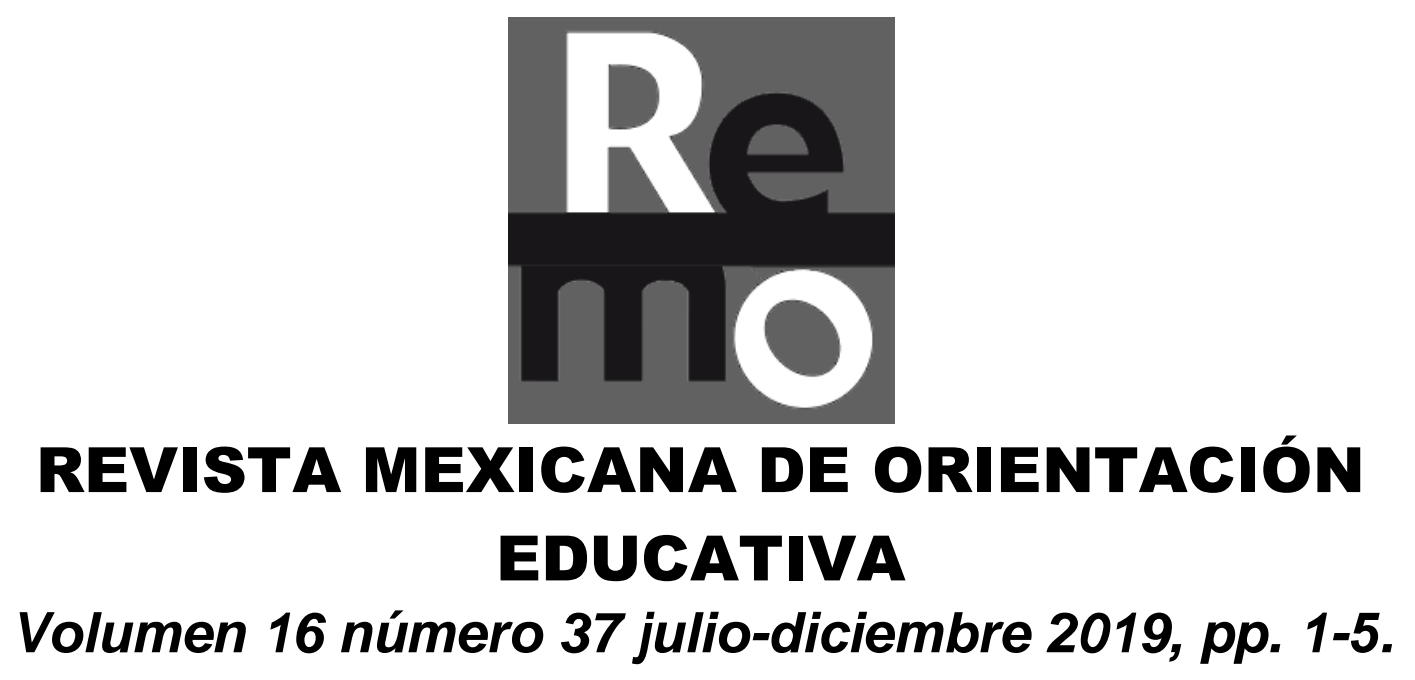

La crisis política y social en Chile 2019

Autor: Dr. Horacio Foladori

Doctor en psicología clínica.

noviembre de 2019

DOI: https://doi.org/10.31206/rmdo182019

\title{
¿Por qué razón el objetivo de la protesta fue el Metro?
}

El Metro de Santiago es uno de los mejores y más modernos del mundo. Desde hace más de cinco años el Estado insiste en eso. Se trata de una red extensa eficiente que transporta a diario más de 2 millones 800 mil personas, de manera rápida y segura. Mucho más rápida que el transporte de superficie. Los gobiernos post dictadura han invertido en la construcción y ampliación del metro y sobre todo porque no contamina como los autobuses y los vehículos particulares. Las últimas dos línea inauguradas este año están totalmente automatizadas al punto de que no tienen conductor. Además las estaciones están equipadas con un dispositivo que 
protege al usuario de tal manera que un doble sistema de puertas se abre cuando el metro llega, nadie puede caerse a las vías ni el metro puede ser utilizado para suicidarse. Un metro digno de Japón o de Alemania, Chile esta orgulloso de él. Los últimos gobiernos han puesto el énfasis en su ampliación, se han previsto construcciones hasta 2027. Una red que atraviesa toda la ciudad y seguirá creciendo. Un metro limpio, bien cuidado, agradable y amplio.

¿Por que razón entonces hay que atacarlo? ¿Como explicar el ensañamiento de que ha sido objeto el 18-O, lo que ha ocasionado que el Metro haya tenido que suspender su servicio en todas sus líneas? ¿Cómo dar cuenta del masivo apoyo que han tenido aquellos que lo han atacado a pesar de ser conscientes de que a partir del lunes 21 de octubre Santiago de Chile será un infierno, que las personas tendrán que disponer de mucho mas tiempo para ir al trabajo y para regresar de él, que se recargará con autobuses la circulación en la ciudad lo que incrementará la contaminación y generará múltiples atochamientos en el tránsito, que todos sufriremos más por tener que viajar en buses repletos de personas y que todo el mundo estará mucho más tenso que antes lo que generará discusiones acaloradas por cualquier motivo.

Otra vez los pingüinos (estudiantes secundarios) están no solo en el ojo del huracán sino que crearon el huracán como lo estuvieron hace ya muchos años cuando con sus movilizaciones pusieron sobre el tapete político la exigencia de una educación gratuita, la cual aún no se logra a cabalidad.

Los pingüinos iniciaron el lunes pasado 14 de octubre el dispositivo de la EVASION, esto es una manera de ingresar al metro masivamente, saltar por los torniquetes 0 pasar por debajo de ellos y acceder a los andenes directamente sin pagar boleto. Fue la respuesta inicial a la suba de $\$ 30$ al boleto del metro. Hay que decir que el gobierno no subió el boleto estudiantil, por lo que creyó tal vez que los secundarios no se verían afectados. Las personas entrevistadas leyeron este acto de la EVASION como una muestra de solidaridad de los hijos con los padres, con los adultos y declaran por ello que el movimiento ha de ser apoyado aunque se tengan reparos en los "métodos utilizados por los jóvenes". "Ya basta de que los 
estudiantes saquen la voz por nosotros" declara una señora entrevistada por la TV. Los pingüinos han llamado al público a sumarse al método y así desde el lunes el movimiento ha ido creciendo significativamente hasta llegar al 18: Un ataque certero a un transporte de lujo. Los daños alcanzan los 300 millones de dólares, una cifra impensable. Primero saltaron por los encima de los torniquetes, luego los empezaron a romper, más tarde comenzaron a romper los cajeros automáticos, las casetas de validación de la tarjeta, el mobiliario, los ascensores las rejas de ingreso y las escaleras mecánicas, claro está que para ese entonces ya se habían sumado otros sectores de la población. El 18 por la noche se prende fuego a varias estaciones de metro, cerca de 80 de ellas han de ser cerradas por las autoridades y están seriamente afectadas. La reparación llevará meses, Santiago tiene un aspecto sombrío y militarizado (respuesta del gobierno) a 15 días de la reunión de la APEC .

El asunto de la suba del boleto tan solo funciona como factor desencadenante, muchos políticos reconocen una intensa rabia acumulada y muestran la sordera del gobierno para hacerse cargo de los problemas que preocupan a la gente. "No más abusos", dice una inscripción en un vagón. Los periodistas utilizan este argumento para implícitamente denunciar la irresponsabilidad del movimiento y su falta de sentido, no comprenden - o no desean hacerlo - la relación entre la suba del boleto y la descomunal respuesta de la población la noche del 18. Para el gobierno solo hay actos vandálicos, manipuleo de agitadores de tendencia anárquica que desean sembrar el caos y el desorden social: contesta con la militarización. El presidente del sindicato del Metro declara: "El gobierno ha transformado el caos vial en caos social".

¿De qué están hartos los chilenos? La gente resiste y aguanta. La vuelta a la democracia bajo el lema "la alegría ya viene" que consiguió instalar el rechazo a la dictadura y el inicio de la transición, no trajo la alegría anhelada. Los gobiernos de la concertación, administraron el neoliberalismo implantado por la dictadura: privatización del sistema educacional, privatización de la salud, privatización del sistema de previsión social y pensiones, privatización de cada una y todas la 
empresas del Estado ( salvo Codelco ya que por ley el $10 \%$ de sus ingresos tenía destino en las Fuerzas Armadas.) Todo era y es negocio y una economía abierta genera sistemáticamente subas en las cuotas mientras que los salarios se rigen por el salario mínimo que tiene que ser aprobado por el Estado. Lo sueldos son bajos y se han mantenido bajos. Los bancos (sobre todo el sistema de hipotecas), las compañías aseguradoras, las asociaciones de fondos de pensiones (AFP), las compañía de seguros de salud (ISAPRES), todos ellos tienen año a año enormes ganancias. La impunidad crece.

Se descuben las colusiones para subir los precios entre las grandes compañías que sostienen cadenas de farmacias, colusiones entre las empresas que producen pollos, entre empresas que producen papel, entre bancos, etc. Se descubren desfalcos millonarios en el ejército, en carabineros, en el manejo corrupto de los gastos reservados de los grandes generales, muchos de ellos retirados y cobrando además suculentas pensiones. Se descubren las alianzas y los financiamientos ilegales de campañas políticas de diputados y senadores de todos los partidos, en los que dueños de empresas en manos de familiares de Pinochet han destinado fondos a diputados de grupos de izquierda...

La desigualdad en Chile es cosa seria, está en el mismo rango que Brasil y México.

Con un salario mínimo de alrededor de 400 dolares mensuales jel $13 \%$ se va en transporte! ¡Es mucha plata! Chile es un país caro, ninguna familia puede vivir con eso. Los índices de endeudamiento son elevadísimos lo que transforma la vida en un trabajar para pagar deudas, en una sociedad que abraza el consumo.

El Metro es de lujo, pero ese lujo para el desplazamiento no mejora en nada las preocupaciones diarias de la gente. Ese dinero que se va al metro no mejora el ingreso de las familias, el gobierno no mejora sustancialmente al sistema de salud estatal porque está apañado con las Isapres y trabaja para ellas, congela los planes de educación gratuita porque los colegios y universidades son una mina de oro, sostiene un sistema de AFP ( fundado por el hermano del Presidente) porque así los empresarios tienen un enorme monto de dinero de los trabajadores para utilizar 
en inversiones diversas, lo que les reporta enormes ganancias pagando pensiones ridículas. Hace unos años nace el movimiento NO MAS AFP; el gobierno no quiere saber nada de todo eso.

Un Metro de lujo se justifica para un público que vive bien, pero el pueblo vive tensionado, estresado por un sistema exigente en lo laboral que exprime y no retribuye. Chile tiene una de las tasas de suicidios mas alta del mundo. El Estado ignora estas diferencias, las desigualdades socio-económicas son extremas. Ahora viene la pregunta: ¿Un metro para qué? ¿ Para llegar más rápido al trabajo, para trabajar más para que la empresa aumente su plusvalía? Un metro que crea una ilusión de bienestar y una imagen de que Chile crece cuando lo único que crece es el capital de las empresas que a su vez son favorecidas por el gobierno de turno? ¿Un Metro de lujo para que los políticos se saquen la foto a costa de la paupérrima situación de miles de familia que vivirán para pagar deudas? ¿Inversiones en un Metro de lujo cuando miles de familias no pueden pagar la renta mensual o tienen que vivir en campamentos en condiciones infrahumanas ya que no hay casas disponibles que habitar? ¿La necesidad de un Metro de lujo ... en rigor, a quien beneficia?

EVADE (que aparece pintado en muchas estaciones) no es una consigna solo para el Metro, es una propuesta para transformar la vida, es una fórmula de desobediencia civil. Cala hondo en la población que recurre pacíficamente a los cacerolazos para manifestar, como en dictadura, su descontento tanto como su sufrimiento. Otro letrero propone "Abajo el Estado". 